\title{
A Grateful Disposition Promotes the Well-Being of Women with Breast Cancer Through Adaptive Coping
}

\author{
Joanna Tomczyk' \\ Izabela Krejtz' \\ Monika Kornacka ${ }^{2}$ \\ John B Nezlek ${ }^{3,4}$
}

'Institute of Psychology, SWPS University of Social Sciences and Humanities, Warsaw, Poland; ${ }^{2}$ Institute of Psychology, SWPS University of Social Sciences and Humanities, Katowice, Poland; ${ }^{3}$ Institute of Psychology, SWPS University of Social Sciences and Humanities, Poznań, Poland; ${ }^{4}$ Department of Psychological Sciences, College of William and Mary,

Williamsburg, VA, USA
Correspondence: Joanna Tomczyk SWPS University of Social Sciences and Humanities, Chodakowska 19/3I, 03-8I5, Warsaw, Poland

Tel +48225179600

Email jtomczyk@swps.edu.pl
Introduction: Gratitude has been studied as a disposition that reflects the extent to which people appreciate what they have in life knowing that it has not been given to them forever. Being grateful has been found to promote quality of life, which is why it may be used to cope in difficult times including during breast cancer diagnosis and treatment.

Methods: Dispositional gratitude was examined in relation to the well-being of women with breast cancer. In the current study, 119 women with breast cancer completed questionnaires that measured gratitude, well-being, coping styles, depression, and anxiety.

Results: Correlational analyses found that dispositional gratitude was positively correlated with well-being $(p<0.001)$ and was negatively correlated with depression $(p<0.05)$ and anxiety $(p<0.05)$. Gratitude was also positively correlated with the use of task-oriented $(p<$ $0.05)$ and socially oriented coping $(p<0.01)$ techniques. Analyses of mediation using PROCESS found that the use of task-oriented and socially oriented coping mediated relationships between gratitude and well-being, between gratitude and anxiety, and between gratitude and depression.

Conclusion: In terms of application, the present results suggest that among women who have breast cancer, increasing dispositional gratitude may increase adaptive coping, which in turn will increase their well-being.

Keywords: gratitude, breast cancer, well-being, coping, depression, anxiety

\section{Introduction}

Although improvements in the treatment of breast cancer in the last decade have led to high survivability, the experience of breast cancer remains a stressful, threatening, and terrifying experience for many women and their families. ${ }^{1}$ Presently, breast cancer is considered a chronic illness, associated with physical pain, severe stress, and decreased psychological well-being. Moreover, it may be that the severity of these emotional effects is underestimated by some health care professionals. ${ }^{2}$

The present study was designed to increase our understanding of the factors that influence the well-being of breast cancer patients. The starting point for the study was the growing body of research suggesting that dispositional gratitude is positively related to well-being. ${ }^{3-5}$ Our study was designed to identify the factors that influence the well-being of breast cancer patients by examining relationships between gratitude and well-being and by examining how coping strategies mediate relationships between gratitude and well-being. 


\section{Well-Being and Mental Health During the Breast Cancer Experience}

The diagnostic process of breast cancer often leads to decreased well-being. The moment that is reported to be the most distressing is just before the diagnosis when women are waiting for their biopsy reports. ${ }^{6}$ Thereafter, the level of stress experienced at the beginning of the treatment process, which is fueled by cancer-related intrusive thoughts and financial concerns, has been shown to be positively related to the later development of clinical depressive symptoms. ${ }^{7}$

The first few weeks after the diagnosis are also stressful. ${ }^{6}$ During this time, many women experience strong negative emotions, denial, and emotional reactions such as uncontrolled crying. ${ }^{6}$ The importance of the initial stages of the breast cancer experience was supported by the results of Brandão et al. ${ }^{8}$ In their review of 41 longitudinal studies, referring to psychosocial factors "near diagnosis" (eg, optimism, coping, anxiety, social support,) Brandão et $\mathrm{al}^{8}$ concluded that psychosocial factors predict later physiological adjustment, for example, optimism is related to higher engagement in treatment, and perceived support is related to lower emotional reactivity.

Although treatment holds the promise of the control of the disease, if not a cure, it can also be associated with distress. Often, there are painful and unexpected challenges that add to the burden posed by the disease. These can include adverse side effects of chemotherapy, such as hair loss, nausea, early-onset menopause, ulcers, sexual dysfunction, and memory lapses, ${ }^{9}$ as well as side effects of radiation therapy, such as insomnia, fatigue, and pain. ${ }^{10}$ Undergoing a mastectomy tends to decrease women's selfesteem and body image, thus adding to their distress, ${ }^{11,12}$ although the possibility of reconstruction or conservation surgery may lower body image disturbance. ${ }^{13}$ The progressive deterioration of a woman's well-being thus begins a vicious circle that is difficult to break, as high levels of psychological distress further affect the physical state of patients, increasing the perceived levels of pain and fatigue. ${ }^{14}$

Cancer patients often develop depression or anxiety disorders ${ }^{15}$ however, it is difficult to estimate the prevalence of mental health outcomes in this population as psychological distress among cancer patients tends to be underdiagnosed. ${ }^{16} \mathrm{~A}$ meta-analysis of psychiatric interview-based studies on mental health and cancer found that about $25 \%$ of patients in palliative care suffer from some type of depression, ${ }^{15}$ while a systematic review of studies on depression in palliative care patients suggests a prevalence of up to $49 \%{ }^{16}$

Other common mental health outcomes, often accompanying depression, are adjustment disorder, anxiety, and other mood disorders. ${ }^{15}$ All of these are associated with strong emotional responses to cancer and the difficulties in coping with it. It has been estimated that stress is responsible for over $50 \%$ of the variance in patients' depressive symptoms. ${ }^{7}$ Moreover, breast cancer is one of four cancer types associated with the highest risk of depression. ${ }^{17}$ Depression among women with breast cancer is particularly maladaptive because it may be associated with a reluctance to follow prescribed treatment ${ }^{18}$ and with increased mortality. ${ }^{19}$

Anxiety and depression have been found to affect from $20 \%$ to $40 \%$ of all cancer patients at some point in their treatment, ${ }^{15}$ with women tending to report greater anxiety and depression than men across all cancer types, which is consistent with gender differences in these mental outcomes in a healthy population. ${ }^{20}$ Even after recovery, over $70 \%$ of breast cancer survivors fear that their cancer will reoccur, and almost 30\% experience mood problems including maladaptive levels of anxiety. ${ }^{21}$

\section{Gratitude Promotes the Well-Being of Breast Cancer Patients}

Studies have consistently found that gratitude is positively related to well-being among breast cancer patients. ${ }^{22-25}$ Gratitude is a positive emotion that can also be conceptualized as a personal trait. ${ }^{5}$ Compared to those low in gratitude, people who have high levels of trait gratitude find it easier to notice and appreciate positive aspects of their lives, in part because they are aware that life is short and that everything they have should be considered a gift. $^{5}$

Algoe and Stanton ${ }^{22}$ studied the social function of gratitude in a group of women with breast cancer. Fiftyfour patients were asked to write a story about something positive that someone did for them recently, and they answered a series of questions about their emotional response and appraisal of the situation. Then, they were asked to think of the good things people did to them recently in general and rate how often they felt each of the set of emotions (including thankfulness, gratitude, and appreciation). Those who felt gratitude and were not ambivalent about expressing it experienced an increase in perceived social support at a three-month follow-up. 
Ruini and Vescovelli ${ }^{23}$ examined relationships between the dispositional trait of gratitude and psychological health among breast cancer patients. In their study, breast cancer patients were divided into two groups depending on their dispositional gratitude, and they answered questions about their functioning (post-traumatic growth, psychological well-being, and physical symptoms). They found that more grateful individuals experienced more posttraumatic growth, more positive emotions, and less distress. Ruini and Vescovelli ${ }^{23}$ concluded that the trait of gratitude plays an important role in post-traumatic growth and in determining the well-being of breast cancer patients.

Two experimental studies have examined the wellbeing of women with breast cancer and found support for the causal sequence that increases in gratitude lead to increases in well-being. In the study on breast cancer survivors by Otto et $\mathrm{al}^{25}$ half of the participants wrote a letter of gratitude to a chosen person, every week for 6 weeks; the other half was the control group and simply described their weekly events. Otto et $\mathrm{al}^{25}$ found that the fear of a recurrence of cancer decreased from pre- to posttesting for women who wrote gratitude letters, whereas it did not in the control condition. These findings are particularly important because this type of fear affects patients' well-being for years after they finish treatment and after they are considered to be cancer survivors. ${ }^{26}$

Along these same lines, in a 14-day diary study of women with breast cancer, Sztachańska et $\mathrm{al}^{24}$ found that women who listed the things for which they felt grateful each day reported higher social support, self-esteem, optimism, acceptance of illness, and other measures of adaptive psychological functioning than women in a control condition who did not list the things for which they were grateful. These effects were not moderated by how much time had passed since they had been diagnosed or the stage of treatment participants were in. These results suggest that increasing the gratitude breast cancer patients experience can lead to increases in well-being, regardless of cancer profile.

\section{Stress-Related Growth and Adaptive Coping}

Although having cancer is psychologically distressing and debilitating, some cancer patients perceive cancer as a kind of a turning point in their lives that can provide valuable, beneficial, and transformational lessons. ${ }^{27}$ As a consequence, patients who perceive cancer in this way can experience positive outcomes and positive personality changes. Such outcomes and changes are often referred to as post-traumatic or stress-related growth. ${ }^{28}$ Some patients report that their cancer experiences helped them change their perspective, develop stronger interpersonal bonds, improve their attitude to life and themselves, and learn to appreciate nature more. ${ }^{29}$

Several factors appear to facilitate stress-related growth, the most influential of which are social support and the use of adaptive (vs maladaptive) coping styles. ${ }^{30}$ Problem-solving coping, sometimes referred to as taskoriented coping, is also positively related to personal growth.

How people cope with cancer can have long-term effects on health outcomes, patients' survival, and overall prognosis. ${ }^{31}$ Adaptive coping mechanisms such as taskoriented coping predict more post-traumatic growth and better health outcomes, while maladaptive coping mechanisms such as avoidance coping predict poorer psychological adjustment and physical health. ${ }^{8,31,32}$ Moreover, a study of health outcomes in breast cancer patients found that psychological adjustment four months after diagnosis was negatively related to the risk of death and relapse 5 and 10 years later. Assuming that initial adjustment reflects the operation of coping mechanisms, this suggests that coping is related to survival, although there is not enough evidence to infer causation. ${ }^{31}$

\section{Coping as a Mediator of Relationships Between Gratitude and Well-Being}

Although consistent, almost all of the research on relationships between gratitude and well-being (among cancer patients or others) does not address issues of why such relationships exist. ${ }^{25}$ What is it about feeling grateful that leads to, or is associated with, enhanced psychological health? Nevertheless, some research suggests that gratitude may promote psychological health because it promotes the use of adaptive coping mechanisms.

In a study involving 236 healthy collegians, Wood et $\mathrm{al}^{33}$ found that dispositional gratitude was positively correlated with adaptive coping (including planning, active coping, and socially oriented strategies) and was negatively correlated with maladaptive coping (including avoidance-oriented strategies). Most important for present purposes, Wood et $\mathrm{al}^{33}$ found that coping mediated the relationship between gratitude and stress. 
Wood et $\mathrm{al}^{33}$ suggested that people with high scores on trait gratitude display better psychological resources, and one such resource is coping. They also suggested that people high in dispositional gratitude demonstrate specific ways of coping that are different from the pattern among people low in dispositional gratitude. Such differences may be explained partly by Fredrickson's Broaden-and-Build Theory. ${ }^{34,35}$ Gratitude, like other positive emotions, broadens the repertoire of adaptive responses and builds long-lasting resources that an individual can use in times of crisis. ${ }^{35}$

Previous research has not examined relationships among gratitude, well-being, and coping among breast cancer patients. One of the important goals of the present study is to determine if the mediational relationships Wood et $\mathrm{al}^{33}$ found would also occur in a sample of women with breast cancer.

\section{The Present Study}

The present study examined how the gratitude of breast cancer patients is related to their well-being and coping styles, and whether coping styles mediate relationships between gratitude and well-being. Participants in the study were female breast cancer patients who completed a series of questionnaires about their level of dispositional gratitude, well-being, depression, and anxiety. We also measured coping using a multi-dimensional measure of coping styles. ${ }^{36} \mathrm{In}$ general, we expected that a) gratitude would be positively related to well-being, b) adaptive coping, defined as taskoriented and socially oriented coping, would be positively related to well-being, c) adaptive coping would mediate relationships between gratitude and well-being.

\section{Materials and Methods}

\section{Participants}

Participants were 119 women $\left(M_{\text {age }}=48.4, S D=10.9\right)$. They were either current or former breast cancer patients to whom a collaborating oncological foundation had provided or was providing care during their treatment. Demographic information about the sample is presented in the Results section.

\section{Procedure}

Participants were contacted via an oncological foundation located in Warsaw, Poland. They were invited to take part in a study on the well-being of women with breast cancer. Participants provided written informed consent, and completed measures using a secure website. The procedure was approved by the Ethics Committee of SWPS University of Social Sciences and Humanities, Warsaw, Poland; approval no. 53/2020. The study was conducted in accordance with the Declaration of Helsinki.

\section{Measures}

At the beginning of the study, participants provided demographic information, and copies of the items and scales we used and the data that were analyzed in this paper are available online at Open Science Framework: https://osf.io/jv8dr/? view only=49720b1e100b415fb3a89e6e1aab8cf6.

\section{Dispositional Gratitude}

Dispositional gratitude was measured using the Gratitude Questionnaire (GQ6). ${ }^{3}$ Participants rated six items using a scale with endpoints labeled strongly disagree (1) to strongly agree (7). The Cronbach's alpha for the full, sixitem scale was 0.69 . Alpha increased to 0.79 when the last item was deleted ("Long amounts of time can go by before I feel grateful to something or someone"). Given this, we dropped this item from our analyses, and we used the remaining five items as a measure of dispositional gratitude. Dispositional gratitude was defined as the mean response to these five items. Alphas for all scales are presented in Table 1.

Table I Descriptive Statistics and Correlations for Measures

\begin{tabular}{|c|c|c|c|c|c|c|c|c|c|c|}
\hline Measure & $M$ & $S D$ & $\alpha$ & (2) & (3) & (4) & (5) & (6) & (7) & (8) \\
\hline (I) gratitude & 5.69 & 1.14 & 0.80 & $0.43 * * *$ & $-0.2 I^{*}$ & $-0.20^{*}$ & $0.19 *$ & 0.03 & $0.39 * *$ & 0.02 \\
\hline (2) well-being & 3.47 & 0.74 & 0.75 & & $-0.57 * * *$ & $-0.65 * * *$ & $0.37 * * *$ & $-0.4 I^{* * *}$ & $0.37 * * *$ & $-0.19 *$ \\
\hline (3) depression & 15.7 & 12.4 & 0.93 & & & $0.76 * *$ & $-0.34 * * *$ & $0.65 * * *$ & $-0.40 * *$ & $0.21 *$ \\
\hline (4) anxiety & 2.22 & 0.53 & 0.84 & & & & $-0.33 * * *$ & $0.73^{* * *}$ & $-0.37 * * *$ & $0.27 * *$ \\
\hline (5) task coping & 3.68 & 0.45 & 0.83 & & & & & $-0.21^{*}$ & $0.40 * * *$ & -0.07 \\
\hline (6) emotion coping & 2.66 & 0.73 & 0.92 & & & & & & -0.13 & $0.23^{*}$ \\
\hline (7) social coping & 3.62 & 0.69 & 0.72 & & & & & & & 0.10 \\
\hline (8) distraction coping & 2.75 & 0.50 & 0.67 & & & & & & & \\
\hline
\end{tabular}

Notes: $*_{p}<0.05,{ }^{* *} p<0.01$. ${ }^{* * *} p<0.001$. 


\section{Psychological Well-Being}

We measured psychological well-being with five items taken from the WHO Quality of Life-BREF, ${ }^{37}$ Diener et al, ${ }^{38}$ and Scheier et al. ${ }^{39}$ Sample items: "I feel satisfied with myself", "I look into the future with optimism". Participants rated each item using a five-point scale (1=Strongly disagree, $5=$ Strongly agree). Psychological well-being was defined as the mean response to these five items, and the items were scored such that higher scores represented greater wellbeing.

\section{Depression}

Depressive symptoms were measured using the Center for Epidemiological Studies Depression Scale. ${ }^{40}$ Using a scale with endpoints labeled rarely (0) to most of the time (3), participants indicated the frequency with which they had experienced 20 symptoms of depression during the past week. Consistent with previous practice, scores on the CESD were calculated as a sum of the 20 responses, and higher scores represented stronger symptoms of depression.

\section{Anxiety}

Anxiety was measured using ten items taken from the trait subscale of the State-Trait Anxiety Inventory, ${ }^{41}$ eg, "I feel nervous and restless", "I worry too much over something that really doesn't matter". Participants responded using a scale with endpoints labeled (1) almost never and (4) almost always. Anxiety was defined as the mean response to ten items, and the items were scored such that higher scores represented greater anxiety.

\section{Stress Coping Style}

How participants coped with stress was measured using the Coping Inventory of Stressful Situations. ${ }^{36,42}$ The scale has three primary subscales: emotion-oriented coping, task-oriented coping, and avoidance coping. As discussed by Endler and Parker, ${ }^{42}$ the avoidance coping items can be used to create socially oriented coping and distraction coping subscales, which we did. Participants rated each item based on how they deal with problematic situations, on a scale from never (1) to very often (5). Coping styles were defined as the mean response to the items on each scale, with higher scores representing greater use of a type of style.

\section{Analytical Plan}

The primary focus of the present study was to examine if adaptive coping styles mediated relationships between gratitude and well-being. Before testing this relationship, we examined correlations among our measures. We then conducted a series of mediation analyses to estimate the direct and indirect effect of gratitude on well-being, model 4 in PROCESS. ${ }^{43}$ To examine indirect effects, we used bootstrapping with 10,000 samples, and we report $95 \%$ confidence intervals for effects.

\section{Results}

\section{Demographic Information}

The mean number of months participants had known about their illness was $41.9(\min =1, \max =206 ; S D=41.8)$. Most participants, 64.7\%, were from major cities (more than 150,000 citizens), $54.6 \%$ were married, $21 \%$ were divorced, $16 \%$ were single, and $8.4 \%$ were widows. $54.6 \%$ of participants were employed, $12.6 \%$ were students, $9.2 \%$ were unemployed, $10.1 \%$ were on sick leave, and $6.7 \%$ were retired. A vast majority $(83.2 \%)$ had at least one child, $39.5 \%$ lived together with a husband and a child or children. $22.7 \%$ lived alone and $17.6 \%$ lived with a husband only.

In terms of their illness history, $69.7 \%$ had already finished chemotherapy, $20.2 \%$ were undergoing chemotherapy while they participated in the study, 10.1\% have not yet. Moreover, 55.5\% had finished radiotherapy, $10.9 \%$ have not started yet, $33.6 \%$ did not need radiotherapy, 55\% had undergone a mastectomy, and $89.1 \%$ indicated that they had surgery other than a mastectomy. This last statistic suggests that some participants had undergone more than one surgery related to breast cancer.

\section{Correlations Between Gratitude, Coping, and Psychological Functioning}

Descriptive statistics, including Cronbach's alphas for the measures and correlations between them, are presented in Table 1. As can be seen from the table, all measures had what Shrout ${ }^{44}$ defined as "moderate" reliability (0.61 to $0.80)$, and most had "substantial" reliability $(0.81+)$. Also, the means for all measures were sufficiently far from the endpoints of each scale to indicate that floor and ceiling effects were not problems.

The correlations were consistent with our predictions. Gratitude was positively correlated with well-being ( $p<$ $0.001)$, task-oriented coping $(p<0.05)$, and socially 
oriented coping $(p<0.01)$, and was negatively correlated with depression $(p<0.05)$, and anxiety $(p<0.05)$. Taskoriented and socially oriented coping was positively related to well-being ( $p<0.001$ for both), and negatively with depression ( $p<0.001$ for task, $\mathrm{p}<0.01$ for social), and anxiety ( $p<0.001$ for both). Emotional coping and distraction coping were negatively correlated with wellbeing $(p<0.001)$, and positively with depression $(p<$ 0.001 for emotion, $\mathrm{p}<0.05$ for distraction), and anxiety ( $p<0.001$ for emotion, $p<0.01$ for distraction).

Three measures, religiosity $(M=2.69, S D=0.61)$, months since diagnosis $(M=41.9, S D=41.8)$, and age are not presented in Table 1. Religiosity was not significantly correlated with any of the other measures. Time since diagnosis was significantly correlated only with the use of social coping strategies, $r(119)=0.19, p<0.05$, and age was significantly correlated only with emotional coping, $r(119)=-0.22$, $p<0.05$.

\section{Coping as a Mediator of the Relationships Between Gratitude and Well-Being}

Similar to Wood et al, ${ }^{33}$ we examined how coping styles mediated the relationships between (1) gratitude and well-being, (2) gratitude and anxiety, (3) gratitude and depression. Figure 1 presents the theoretical mediation model and explains the estimated coefficients. In terms of the effects labeled in the diagram, the $a$ path is the same for analyses that involve gratitude and the same mediator. A summary of the results of these analyses, the significance of indirect and direct effects for combinations of mediators and outcomes are presented in Table 2 .

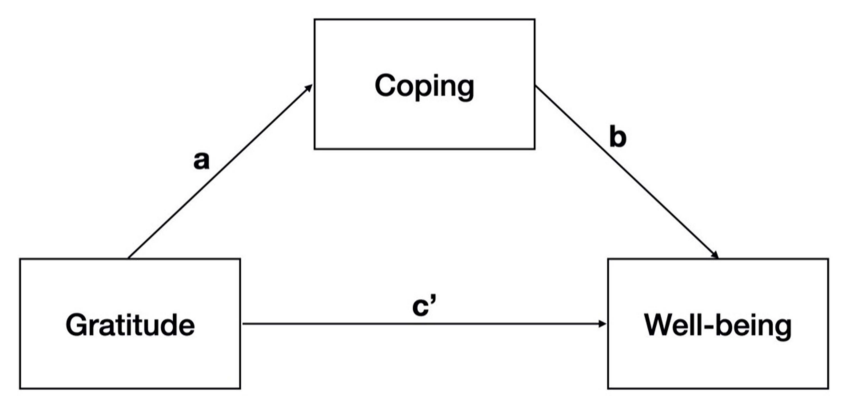

Figure I Mediational model.

Notes: a - relationship between gratitude and coping; b - relationship between coping and well-being controlling for gratitude; c' - direct effect of gratitude on wellbeing controlling for coping; ab - indirect effect of gratitude on well-being.
Table 2 Summary of Mediational Analyses: Indirect and Direct Effects of Gratitude on Outcomes

\begin{tabular}{|l|l|c|c|}
\hline Mediator & Outcome & Indirect Effect & Direct Effect \\
\hline Task-oriented coping & Well-being & $\begin{array}{l}\text { Significant } \\
\text { Significant } \\
\text { Significant }\end{array}$ & $\begin{array}{c}\text { Significant } \\
\text { Not significant } \\
\text { Not significant }\end{array}$ \\
\hline Socially oriented coping & Well-being & Significant & Significant \\
& Anxiety & Significant \\
& Sepression & Significant & $\begin{array}{c}\text { Not significant } \\
\text { Not significant }\end{array}$ \\
\hline
\end{tabular}

\section{Task-Oriented Coping}

The estimated coefficient $a$ in the analyses in which taskoriented coping was the mediator was $0.08(S E=0.04, t=$ $2.14, p=0.03)$. The total mediational model for psychological well-being was significant $\left(R^{2}=0.26, F(2,116)=\right.$ 20.92, $p<0.001)$. The total effect of gratitude on wellbeing, normally represented as $c$, was $0.28(S E=0.05, t=$ $5.08, p<0.001, \mathrm{CI}[0.17,0.38])$. This total effect represented the sum of the direct effect of gratitude on well-being, $c^{\prime}=$ $0.24(S E=0.05, t=4.53, p<0.001$, CI $[0.13,0.34])$ and the indirect effect of gratitude on well-being through taskoriented coping, $a b=0.04$ (boot $S E=0.02$, bootstrapped confidence interval (bootCI) [0.002, 0.09]). The direct effect of task-oriented coping on well-being was also significant, $b=0.48(S E=0.13, t=3.65, p<0.001$, CI $[0.22,0.75])$. The significant indirect effect of gratitude on well-being indicated that task-oriented coping mediated the relationship between gratitude and psychological well-being.

A similar analysis with anxiety as an outcome found that the total mediational model was significant $\left(R^{2}=\right.$ $0.13, F(2,116)=8.38, p<0.001)$. The total effect of gratitude on anxiety $(c)$ was $-0.095(S E=0.04, t=2.23$, $p<0.03$, CI $[-0.18,-0.01])$. This total effect represented the sum of the direct effect of gratitude on anxiety, $c^{\prime}=$ $-0.07(S E=0.04, t=1.63, p=0.11$, CI $[-0.15,0.01])$ and the indirect effect of gratitude on anxiety through taskoriented coping, $a b=-0.03$ (boot $S E=0.02$, bootCI $[-0.07,-0.001])$. The direct effect of task-oriented coping on anxiety was also significant, $b=-0.35(S E=0.10, t=$ $3.37, p<0.01$, CI $[-0.56,-0.14])$. The significant indirect effect of gratitude on anxiety indicated that task-oriented coping mediated the relationship between gratitude and anxiety. Moreover, although there is some debate about the use of the term "full mediation", 45 we should note that the direct effect of gratitude on anxiety was not significant ( $p=0.11)$ after task-oriented coping was included as a mediator. 
A similar analysis with depression as an outcome found that the total mediational model was also significant $\left(R^{2}=\right.$ $0.14, F(2,116)=9.34, p<0.001)$. The total effect of gratitude on depression (c) was -2.30 ( $S E=0.98, t=2.34, p<0.03$, CI $[-4.25,-0.35])$. This total effect represented the sum of the direct effect of gratitude on depression, $c^{\prime}=-1.64(S E=0.96$, $t=1.71, p=0.09$, CI $[-3.53,0.26])$ and the indirect effect of gratitude on depression through task-oriented coping, $a b=$ -0.66 (bootSE $=0.41$, bootCI $[-1.60,-0.03]$ ). The direct effect of task-oriented coping on depression was also significant, $b=-8.57$ ( $S E=2.41, t=3.56, p<0.001$, CI [-13.34, $-3.80])$. The significant indirect effect of gratitude on depression indicated that task-oriented coping mediated the relationship between gratitude and depression. The direct effect of gratitude on depression was not significant after task-oriented coping was included as a mediator $(p=0.09)$. A summary of the results of these analyses is presented in Table 3.

\section{Socially Oriented Coping}

We conducted a parallel series of analyses that examined if socially oriented coping mediated relationships between gratitude and psychological functioning. The $a$ path from gratitude to socially oriented coping was the same for all these analyses, $0.24(\mathrm{SE}=0.05, t=4.58, p<0.001)$.

The first model, examining if socially oriented coping mediated the relationship between gratitude and psychological well-being, was significant $\left(R^{2}=0.23, F(1,116)=\right.$ $17.3, p<0.001)$. The total effect of gratitude on well-being (c) was the same as it was in the previous analysis of taskoriented coping (0.28). This total effect represented the sum of the direct effect of gratitude on well-being, which in this analysis was $c^{\prime}=0.22(S E=0.06, t=3.74, p<0.001, \mathrm{CI}$ $[0.17,0.38])$ and the indirect effect of gratitude on wellbeing through socially oriented coping, $a b=0.06$ (bootSE = 0.03 , bootCI $[0.008,0.12])$. The direct effect of socially oriented coping on well-being was also significant, $b=$
$0.26(S E=0.09, t=2.72, p<0.01$, CI [0.07, 0.45]). As expected, the significant indirect effect of gratitude on wellbeing indicated that socially oriented coping mediated the relationship between gratitude and well-being.

The second model, examining if socially oriented coping mediated the relationship between gratitude and anxiety, was also significant $\left(R^{2}=0.14, F(2,116)=9.35, p<0.001\right)$. The total effect of gratitude on anxiety $(c)$ was the same as it was in the previous analysis of task-oriented coping (-0.095). This total effect represented the sum of the direct effect of gratitude on anxiety, $c^{\prime}=-0.03(S E=0.04, t<1$, ns, CI $[-0.12,0.05])$ and the indirect effect of gratitude on anxiety through socially oriented coping, $a b=-.06$ (bootSE $=0.02$, bootCI $[-0.12,-0.02])$. The direct effect of socially oriented coping on anxiety was also significant, $b=-0.26(S E=0.07$, $t=3.63, p<0.001$, CI $[-0.41,-0.12])$. As expected, the significant indirect effect of gratitude on anxiety indicated that socially oriented coping mediated the relationship between gratitude and anxiety. Moreover, as was the case with task-oriented coping, after including socially oriented coping as a mediator, the direct effect of anxiety was not significant $(t<1)$.

The last model, examining if socially oriented coping mediated the relationship between gratitude and depression, was also significant $\left(R^{2}=0.16, F(1,116)=11.33\right.$, $p<0.001)$. The total effect of gratitude on depression (c) was the same as it was in the previous analysis of taskoriented coping $(-2.30)$. This total effect represented the sum of the direct effect of gratitude on depression, $c^{\prime}=$ $-0.71(S E=1.00, t<1, \mathrm{~ns}, \mathrm{CI}[-2.70,1.28])$ and the indirect effect of gratitude on depression through socially oriented coping, $a b=-1.59$ (bootSE $=0.60$, bootCI $[-2.94,-0.60])$. The direct effect of socially oriented coping on depressions was also significant, $b=-6.75$ $(S E=1.66, t=4.06, p<0.001$, CI $[-10.04,-3.45])$. As

Table 3 Model Coefficients for Mediational Analysis with Task-Oriented Coping as a Mediator of the Relationship Between Gratitude and Psychological Functioning

\begin{tabular}{|c|c|c|c|c|c|c|c|c|c|c|c|c|c|c|c|c|}
\hline \multirow[b]{2}{*}{ Predictor } & \multicolumn{4}{|c|}{ Stress Coping } & \multicolumn{4}{|c|}{ Well-Being (Outcome) } & \multicolumn{4}{|c|}{ Anxiety } & \multicolumn{4}{|c|}{ Depression } \\
\hline & & Coeff. & $S E$ & $t$ & & Coeff. & $S E$ & $\boldsymbol{t}$ & & Coeff. & $S E$ & $t$ & & Coeff. & $S E$ & $t$ \\
\hline Gratitude & $\mathrm{a}$ & 0.08 & 0.04 & $2.14 *$ & $c^{\prime}$ & 0.24 & 0.05 & $4.53^{* * * *}$ & $c^{\prime}$ & -0.07 & 0.04 & 1.63 & $c^{\prime}$ & -1.64 & 0.96 & 1.71 \\
\hline \multirow[t]{2}{*}{ Task-oriented coping } & & - & - & - & $\mathrm{b}$ & 0.48 & 0.13 & $3.65 * * *$ & $b$ & -0.35 & 0.10 & $3.37^{* *}$ & $b$ & -8.57 & 2.41 & $3.56^{* * * *}$ \\
\hline & \multicolumn{4}{|c|}{$\begin{array}{l}R^{2}=0.04, F(I, I 17)=4.58, \\
p=0.03\end{array}$} & \multicolumn{4}{|c|}{$\begin{array}{l}R^{2}=0.26, F(2,|1| 6)=20.92, p< \\
0.001\end{array}$} & \multicolumn{4}{|c|}{$\begin{array}{l}R^{2}=0.13, F(2,116)=8.38, p< \\
0.001\end{array}$} & \multicolumn{4}{|c|}{$\begin{array}{l}R^{2}=0.14, F(2,116)=9.34, p< \\
0.001\end{array}$} \\
\hline
\end{tabular}

Notes: Coefficients accompanied by ${ }^{* * *} p<0.001$, ${ }^{* *} p<0.01,{ }^{*} p<0.05$, a - relationship between gratitude and coping; $b$ - relationship between coping and psychological functioning controlling for gratitude; c' - direct effect of gratitude on psychological functioning controlling for coping. 
expected, the significant indirect effect of gratitude on depression indicated that socially oriented coping mediated the relationship between gratitude and depression. Moreover, after including socially oriented coping as a mediator, the direct effect of depression was not significant $(t<1)$. A summary of the results of these analyses is presented in Table 4.

\section{Discussion}

As expected, we found that dispositional gratitude was positively related to subjective well-being, which included negative relationships between gratitude and depression and anxiety. These results replicate previous research and suggest that gratitude plays an important role in determining the well-being of women with breast cancer. We also found positive relationships between gratitude and adaptive coping styles (task- and socially oriented coping), whereas we found no relationships between gratitude and maladaptive coping styles (emotional coping and coping using distraction).

Most important, we found that relationships between gratitude and well-being were mediated by adaptive coping styles, whereas they were not mediated by maladaptive coping styles. The results of our study, which we believe is the first to demonstrate such mediational relationships in a sample of women with breast cancer, meaningfully expand our understanding of why gratitude is positively related to the psychological functioning of women with breast cancer.

\section{Gratitude Helps Compensate for Lost Resources}

According to Hobfoll's Conservation of Resources Theory, ${ }^{46}$ stress appears when an individual is threatened with a loss of personal resources. Being diagnosed with cancer can pose such a threat and can cause a major decrease in a person's well-being. In the face of such a life-changing event, how well a person functions psychologically depends on several factors, including cognitive and behavioral (employed coping strategies), social (actual and perceived support), and personal factors (dispositions which are subject to individual differences).

Previous research has found that people high in dispositional gratitude, compared to those who are low, cope with stress better ${ }^{47}$ and perceive more support from their partners and other people. ${ }^{24}$ Moreover, gratitude may take part in the process of compensation for lost resources, as it allows people to notice and focus on what they have, rather than on what they have lost. Compensation is thought to be "the most effective mechanism for the management of resources", 48 whenever the lost resources cannot be replaced.

\section{Gratitude Builds Long-Lasting Resources}

How dispositional gratitude works in helping cancer patients cope with severe stress might be explained also by Frederickson's Broaden-and-Build Theory. ${ }^{35}$ The theory posits that positive emotions build resources used in coping with difficulties, and they broaden our cognitive spectrum, creativity, and repertoire of behaviors. People with higher levels of dispositional gratitude experience more positive emotions than those with lower levels, particularly in a crisis; therefore, they build the resources that help them cope better. Consistent with the explanation offered by Wood et al, ${ }^{33}$ it seems that grateful people (including cancer patients) may use more positive coping strategies, and the frequent positive emotions they experience as part of these strategies may not only "undo" the adverse effects of anxiety and depression, ${ }^{49}$ but also counter them.

Table 4 Model Coefficients for Mediational Analysis with Socially Oriented Coping as a Mediator of the Relationship Between Gratitude and Psychological Functioning

\begin{tabular}{|c|c|c|c|c|c|c|c|c|c|c|c|c|c|c|c|c|}
\hline \multirow[b]{2}{*}{ Predictor } & \multicolumn{4}{|c|}{ Stress Coping } & \multicolumn{4}{|c|}{ Well-Being (Outcome) } & \multicolumn{4}{|c|}{ Anxiety } & \multicolumn{4}{|c|}{ Depression } \\
\hline & & Coeff. & SE & $t$ & & Coeff. & SE & $t$ & & Coeff. & $S E$ & $\boldsymbol{t}$ & & Coeff. & SE & $\mathbf{t}$ \\
\hline Gratitude & a & 0.24 & 0.05 & $4.58 * * *$ & $c^{\prime}$ & 0.22 & 0.06 & $3.74^{* * * *}$ & $c^{\prime}$ & -0.03 & 0.04 & $<1$ & $c^{\prime}$ & -0.71 & 1.00 & $<1$ \\
\hline \multirow[t]{2}{*}{ Socially oriented coping } & & - & - & - & $b$ & 0.26 & 0.09 & $2.72^{* * *}$ & $b$ & -0.26 & 0.07 & $3.63 * * *$ & $b$ & -6.75 & 1.66 & 4.06 *** \\
\hline & \multicolumn{4}{|c|}{$\begin{array}{l}R^{2}=0.15, F(1,117)=20.98, p< \\
0.001\end{array}$} & \multicolumn{4}{|c|}{$\begin{array}{l}R^{2}=0.23, F(I, I 16)=17.3, p< \\
0.001\end{array}$} & \multicolumn{4}{|c|}{$\begin{array}{l}R^{2}=0.14, F(2,116)=9.35, p< \\
0.001\end{array}$} & \multicolumn{4}{|c|}{$\begin{array}{l}R^{2}=0.16, F(1,116)=11.33, p< \\
0.001\end{array}$} \\
\hline
\end{tabular}

Notes: Coefficients accompanied by $* * * p<0.001$, ${ }^{* *} p<0.01$, a - relationship between gratitude and coping; b relationship between coping and psychological functioning controlling for gratitude; c' - direct effect of gratitude on psychological functioning controlling for coping. 


\section{Mediation: Comparisons with Previous Research}

To our knowledge, Wood et a $\mathrm{l}^{33}$ is the only other study that has examined coping as a mediator of relationships between gratitude and well-being. In two studies of collegians, Wood et $\mathrm{al}^{33}$ measured gratitude using the GQ6 and measured coping using variants of the COPE, ${ }^{50}$ and measured well-being in terms of stress, depression, happiness, and satisfaction with life. They found that coping did not mediate relationships between gratitude and either depression or happiness, that relationships between gratitude and stress were mediated by adaptive coping (positive reinterpretation) and maladaptive coping (behavioral disengagement and self-blame), and that self-blame mediated relationships between gratitude and satisfaction with life.

Although the present results are consistent with the overall conclusion of Wood et $\mathrm{al}^{33}$ that coping mediates relationships between gratitude and well-being, we found relationships that Wood et $\mathrm{al}^{33}$ did not find (ie, that coping mediated the relationships between gratitude and depression). Nevertheless, given the differences between their study and ours in terms of the samples (collegians vs adult women with breast cancer) and the measures (eg, the COPE vs the CISS), it is difficult to compare the two directly. Although the COPE and the CISS measure coping in different ways, conceptually, they both measure what is typically considered adaptive and maladaptive coping, and so our sense is that the differences in the results probably reflect the meaningful differences in the samples. Participants in the present study were coping with a lifechanging and potentially fatal illness. We believe that the present results are generalizable to a population that is facing an important problem.

\section{Limitations and Future Directions}

Although this study provides a valuable insight into how gratitude protects the well-being of women with breast cancer and promotes adaptive coping strategies, it is not without limitations. First of all, the paper describes correlations between trait measures, and it assumes causal directions among these measures. The measures were collected in a cross-sectional design, however, which does not provide a firm basis for making causal inferences.

Due to the correlational design, it is impossible to infer causality or be certain as to what affected the dependent variables. Moreover, the present results could reflect the influence of other unmeasured variables, particularly those that have been shown to be related to coping, such as dispositional optimism, ${ }^{51}$ or trait anger and personality traits. ${ }^{52}$

To date, we are aware of only one paper that has used an experimental procedure to examine relationships between gratitude and coping among women with breast cancer. ${ }^{24}$ Our assumptions regarding the mediation were consistent with their findings that increases in gratitude led to increases in well-being. Although their results do not provide full support for our proposed causal sequence, at the least, they suggest that the fundamental link from gratitude to well-being is viable. We believe that more research is needed to document our full model.

We studied breast cancer, and because of this, our participants were women. It would be interesting to see if the relationships we found would occur for male oncological patients. The available research suggests that in the general population women feel grateful more often than men, ${ }^{53}$ and women report having more dispositional gratitude than men. ${ }^{54}$ It is not clear how such differences would influence the relationships we found.

We also believe future research should examine the role of gratitude in enhancing the well-being of people with other diseases. The current study was focused on studying breast cancer, which is characterized by a very high survivability rate given an early diagnosis, and a low level of malignancy. ${ }^{55}$ Moreover, future research concerning cancer patients should collect information about their stage of illness, prognosis, and detailed history of treatment. These variables need to be accounted for as they might affect the patients' well-being and ability to feel gratitude. More information about the illness could help answer the question of whether the beneficial effect of gratitude is universal for all patients suffering from chronic and potentially life-threatening diseases.

Although we tested coping as a mediator between gratitude and well-being, there might be other variables that can explain this relationship. Further studies could consider including measures of post-traumatic growth, resilience, dispositional optimism, and personality.

Regardless of its limitations, we believe that the present study can help inform practice. It may be valuable for those who are interested in using gratitude training to improve the well-being of breast cancer patients. Given the availability of electronic devices, an eHealth intervention (such as a gratitude diary; see Sztachańska et $\mathrm{al}^{24}$ ), could be a useful tool to encourage the use of adaptive coping strategies through counting one's blessings. The effectiveness of 
eHealth interventions has been proven in the population of women with breast cancer. ${ }^{56}$ The present study found differences in coping strategies are different depending on age and time since diagnosis, therefore it would be worthwhile not only to examine these relationships in future research, but also to target future interventions to the specific needs of various groups of breast cancer patients.

\section{Conclusion}

Determining how to protect patients' well-being, particularly in times of stress, is an important focus of contemporary research. ${ }^{57}$ The results of the present study suggest that gratitude may promote adaptive coping and wellbeing among women with breast cancer. If dispositional gratitude leads to the use of adaptive coping, it is possible that enhancing dispositional gratitude among patients who do not have naturally high levels of it may lead to increases in their use of adaptive coping and in turn, improvements in their well-being. Further research is needed to validate the results of this study.

\section{Acknowledgments}

This research was funded by the National Science Center, Preludium Grant 2016/21/N/HS6/02840 to Joanna Tomczyk. Open access to this article was financed by the Ministry of Science and Higher Education in Poland under the 2019-2022 program "Regional Initiative of Excellence" project number 012/RID/2018/19.

We thank the foundation Fundacja Onkocafe-Razem Lepiej for their help in conducting this study.

\section{Data Accessibility}

The data discussed in this paper are available at https://osf.io/ jv8dr/?view_only=49720b1e100b415fb3a89e6e1aab8cf6.

\section{Disclosure}

The authors declare that this research was conducted in the absence of any commercial or financial relationships that could be construed as a potential conflict of interest.

\section{References}

1. Ben-Zur H, Gilbar O, Lev S. Coping with breast cancer: patient, spouse, and dyad models. Psychosom Med. 2001;63(1):32-39. doi:10.1097/00006842-200101000-00004

2. Caruso R, Nanni MG, Riba MB, Sabato S, Mitchell AJ, Grassi L. Depressive spectrum disorders in cancer: prevalence, risk factors and screening for depression: a critical review. Acta Oncol. 2017;56 (2):146-155. doi:10.1080/0284186X.2016.1266090
3. McCullough ME, Emmons RA, Tsang J. The grateful disposition: a conceptual and empirical topography. J Pers Soc Psychol. 2002;82 (1):112-127. doi:10.1037/0022-3514.82.1.112

4. Kashdan TB, Uswatte G, Julian T. Gratitude and hedonic and eudaimonic well-being in Vietnam war veterans. Behav Res Ther. 2006;44 (2):177-199. doi:10.1016/j.brat.2005.01.005

5. Wood AM, Froh JJ, Geraghty AWA. Gratitude and well-being: a review and theoretical integration. Clin Psychol Rev. 2010;30 (7):890-905. doi:10.1016/j.cpr.2010.03.005

6. Waring AN. Breast cancer: reactions, choices, decisions. Ochsner J. 2000;2(1):40 LP- 46.

7. Golden-Kreutz DM, Andersen BL. Depressive symptoms after breast cancer surgery: relationships with global, cancer-related, and life event stress. Psychooncology. 2004;13(3):211-220. doi:10.1002/ pon.736

8. Brandão T, Schulz M, Matos P. Psychological adjustment after breast cancer: a systematic review of longitudinal studies. Psychooncology. 2016;26. doi:10.1002/pon.4230

9. Dooley LN, Slavich GM, Moreno PI, Bower JE. Strength through adversity: moderate lifetime stress exposure is associated with psychological resilience in breast cancer survivors. Stress Health. 2017;33(5):549-557. doi:10.1002/smi.2739

10. Sharma N, Purkayastha A. impact of radiotherapy on psychological, financial, and sexual aspects in postmastectomy carcinoma breast patients: a Prospective Study and Management. Asia Pac J Oncol Nurs. 2017;4(1):69-76. doi:10.4103/2347-5625.199075

11. Helms RL, O'Hea EL, Corso M. Body image issues in women with breast cancer. Psychol Health Med. 2008;13(3):313-325. doi:10.1080/13548500701405509

12. Sebastián J, Manos D, Bueno M, Mateos N. Body image and self-esteem in women with breast cancer participating in a psychosocial intervention program. Clin Salud. 2007; 18:137-161.

13. Sherman KA, Woon S, French J, Elder E. Body image and psychological distress in nipple-sparing mastectomy: the roles of selfcompassion and appearance investment. Psychooncology. 2017;26 (3):337-345. doi:10.1002/pon.4138

14. Chan CMH, Wan Ahmad WA, Yusof MMD, Ho GF, Krupat E. Effects of depression and anxiety on mortality in a mixed cancer group: a longitudinal approach using standardised diagnostic interviews. Psychooncology. 2015;24(6):718-725. doi:10.1002/ pon. 3714

15. Mitchell AJ, Chan M, Bhatti H, et al. Prevalence of depression, anxiety, and adjustment disorder in oncological, haematological, and palliative-care settings: a meta-analysis of 94 interview-based studies. Lancet Oncol. 2011;12(2):160-174. doi:10.1016/S14702045(11)70002-X

16. Walker J, Holm Hansen C, Martin P, et al. Prevalence of depression in adults with cancer: a systematic review. Ann Oncol. 2013;24 (4):895-900. doi:10.1093/annonc/mds575

17. Massie MJ. Prevalence of depression in patients with cancer. $J$ Natl Cancer Inst Monogr. 2004;2004(32):57-71. doi:10.1093/jncimonographs/lgh014

18. DiMatteo MR, Giordani PJ, Lepper HS, Croghan TW. Patient adherence and medical treatment outcomes: a meta-analysis. Med Care. 2002;40(9):794-811. doi:10.1097/00005650-200209000-00009

19. Satin JR, Linden W, Phillips MJ. Depression as a predictor of disease progression and mortality in cancer patients: a meta-analysis. Cancer. 2009;115(22):5349-5361. doi:10.1002/cncr.24561

20. Linden W, Vodermaier A, MacKenzie R, Greig D. Anxiety and depression after cancer diagnosis: prevalence rates by cancer type, gender, and age. $J$ Affect Disord. 2012;141(2-3):343-351. doi:10.1016/j.jad.2012.03.025

21. Meyer L, Aspegren K. Long-term psychological sequelae of mastectomy and breast conserving treatment for breast cancer. Acta Oncol. 1989;28(1):13-18. doi:10.3109/02841868909111174 
22. Algoe SB, Stanton AL. Gratitude when it is needed most: social functions of gratitude in women with metastatic breast cancer. Emotion. 2012;12(1):163-168. doi:10.1037/a0024024

23. Ruini C, Vescovelli F. The role of gratitude in breast cancer: its relationships with post-traumatic growth, psychological well-being and distress. J Happiness Stud. 2013;14(1):263-274. doi:10.1007/ s10902-012-9330-x

24. Sztachańska J, Krejtz I, Nezlek JB. Using a gratitude intervention to improve the lives of women with breast cancer: a daily diary study. Front Psychol. 2019;10(JUN):1-11. doi:10.3389/fpsyg.2019.01365

25. Otto AK, Szczesny EC, Soriano EC, Laurenceau JP, Siegel SD. Effects of a randomized gratitude intervention on death-related fear of recurrence in breast cancer survivors. Health Psychol. 2016;35 (12):1320-1328. doi:10.1037/hea0000400

26. Deimling GT, Bowman KF, Sterns S, Wagner LJ, Kahana B. Cancerrelated health worries and psychological distress among older adult, long-term cancer survivors. Psychooncology. 2006;15(4):306-320. doi:10.1002/pon.955

27. Cordova MJ, Cunningham LLC, Carlson CR, Andrykowski MA. Posttraumatic growth following breast cancer: a controlled comparison study. Health Psychol. 2001;20(3):176-185. doi:10.1037/02786133.20.3.176

28. Calhoun LG, Tedeschi RG. Positive aspects of critical life problems: recollections of grief. Omega. 1989;20(4):265-272. doi:10.2190/ QDY6-6PQC-KQWV-5U7K

29. O'Connor AP, Wicker CA, Germino BB. Understanding the cancer patient's search for meaning. Cancer Nurs. 1990;13(3):167-175. doi:10.1097/00002820-199006000-00006

30. Armeli S, Gunthert KC, Cohen LH. Stressor appraisals, coping, and post-event outcomes: the dimensionality and antecedents of stress-related growth. J Soc Clin Psychol. 2001;20(3):366-395. doi:10.1521/jscp.20.3.366.22304

31. Watson M, Homewood J, Haviland J. Coping response and survival in breast cancer patients: a new analysis. Stress Health. 2012;28 (5):376-380. doi:10.1002/smi.2459

32. Compas BE, Luecken L. Psychological adjustment to breast cancer. Curr Dir Psychol Sci. 2002;11(3):111-114. doi:10.1111/14678721.00180

33. Wood AM, Joseph S, Linley PA. Coping style as a psychological resource of grateful people. J Soc Clin Psychol. 2007;26 (9):1076-1093. doi:10.1521/jscp.2007.26.9.1076

34. Fredrickson BL. What good are positive emotions? Rev Gen Psychol. 1998;2(3):300-319. doi:10.1037/1089-2680.2.3.300

35. Fredrickson BL, Huppert FA, Baylis N, Keverne B. The broadenand-build theory of positive emotions. Philos Trans $R$ Soc Lond B Biol Sci. 2004;359(1449):1367-1378. doi:10.1098/rstb.2004.1512

36. Endler NS, Parker JD. Multidimensional assessment of coping: a critical evaluation. J Pers Soc Psychol. 1990;58(5):844-854. doi:10.1037/0022-3514.58.5.844

37. Skevington SM, Lotfy M, O'Connell KA; WHOQOL Group. The World Health Organization's WHOQOL-BREF quality of life assessment: psychometric properties and results of the international field trial. A report from the WHOQOL group. Qual Life Res. 2004;13 (2):299-310. doi:10.1023/B:QURE.0000018486.91360.00

38. Diener E, Emmons RA, Larsem RJ, Griffin S. The satisfaction with life scale. J Pers Assess. 1985;49(1):71-75. doi:10.1207/ s15327752jpa4901_13

39. Scheier MF, Carver CS, Bridges MW. Distinguishing optimism from neuroticism (and trait anxiety, self-mastery, and self-esteem): a reevaluation of the life orientation test. J Pers Soc Psychol. 1994;67(6):1063-1078. doi:10.1037/0022-3514.67.6.1063
40. Radloff LS. The CES-D scale: a self-report depression scale for research in the general population. Appl Psychol Meas. 1977;1 (3):385-401. doi:10.1177/014662167700100306

41. Spielberger CD. State-Trait Anxiety Inventory: Bibliography. 2nd ed. Consult Psychol Press; 1989. Available from: https://www.apa.org/pi/ about/publications/caregivers/practice-settings/assessment/tools/traitstate. Accessed May 15, 2021.

42. Endler NS, Parker JD. Coping Inventory for Stressful Situations (CISS): Manual. Toronto, CA: Multi-Health Systems; 1999.

43. Hayes AF. Introduction to Mediation, Moderation, and Conditional Process Analysis: A Regression-Based Approach. 2nd ed. New York: Guilford Press; 2018.

44. Shrout PE. Measurement reliability and agreement in psychiatry. Stat Methods Med Res. 1998;7(3):301-317. doi:10.1177/ 096228029800700306

45. Preacher KJ, Hayes AF. Contemporary approaches to assessing mediation in communication research. In: Hayes AF, Slater MD, Snyder L, editors. The Sage Sourcebook of Advanced Data Analysis Methods for Communication Research. Thousand Oaks, CA, US: Sage Publications, Inc; 2008:13-54. doi:10.4135/9781452272054.n2

46. Hobfoll SE. Conservation of resources: a new attempt at conceptualizing stress. Am Psychol. 1989;44(3):513-524. doi:10.1037/0003066X.44.3.513

47. Krejtz I, Nezlek JB, Michnicka A, Holas P, Rusanowska M. Counting one's blessings can reduce the impact of daily stress. J Happiness Stud. 2016;17(1):25-39. doi:10.1007/s10902-014-9578-4

48. Modrzyński R. Conservation of resources theory by Stevan E. Hobfoll and prediction of alcohol dependent persons' abstinence. Alcohol Drug Addict. 2018;31(2):147-170. doi:10.5114/ain.2018.79992.

49. Fredrickson BL, Mancuso RA, Branigan C, Tugade MM. The undoing effect of positive emotions. Motiv Emot. 2000;24 (4):237-258. doi:10.1023/a:1010796329158

50. Carver CS, Scheier MF, Weintraub JK. Assessing coping strategies: a theoretically based approach. J Pers Soc Psychol. 1989;56 (2):267-283. doi:10.1037//0022-3514.56.2.267

51. Nes LS, Segerstrom SC. Dispositional optimism and coping: a meta-analytic review. Per Soc Psychol Rev. 2006;10(3):235-251. doi:10.1207/s15327957pspr1003_3

52. Rodrigues S, Kaiseler M, Cunha JPS. An overview of anger and anxiety: personality predictors and coping. In: Sofia JFAC\& RMC, editor. Psychology of Emotions, Motivations and Actions. Anger and Anxiety: Predictors, Coping Strategies, and Health Effects. Nova Science Publishers; 2017:3-32.

53. Allen S. The science of gratitude. Univ Calif Berkeley Wellness Lett. 2018;32(6):8.

54. Morgan B, Gulliford L, Kristjánsson K. A new approach to measuring moral virtues: the multi-component gratitude measure. Pers Individ Dif. 2017;107:179-189. doi:10.1016/j.paid.2016.11.044

55. American Cancer Society. Breast cancer facts \& figures 2019-2020. February, 2019. Available from: https:/www.cancer.org/content/dam/ cancer-org/research/cancer-facts-and-statistics/breast-cancer-factsand-figures/breast-cancer-facts-and-figures-2019-2020.pdf. Accessed May 15, 2021.

56. Triberti S, Savioni L, Sebri V, Pravettoni G. eHealth for improving 1226 quality of life in breast cancer patients: a systematic review. Cancer Treat Rev. 2009;1227(74):1-14.

57. Tugade MM, Fredrickson BL. Regulation of positive emotions: emotion regulation strategies that promote resilience. J Happiness Stud. 2007;8(3):311-333. doi:10.1007/s10902-006-9015-4 


\section{Publish your work in this journal}

The International Journal of Women's Health is an international, peerreviewed open-access journal publishing original research, reports, editorials, reviews and commentaries on all aspects of women's healthcare including gynecology, obstetrics, and breast cancer. The manuscript management system is completely online and includes a very quick and fair peer-review system, which is all easy to use. Visit http://www.dovepress.com/testimonials.php to read real quotes from published authors.

Submit your manuscript here: https://www.dovepress.com/international-journal-of-womens-health-journal 